DOI: https://doi.org/10.24867/10BE38Banovic

\title{
PRORAČUN LOKALNE RASPODELE SNAGE GUBITAKA U MAGNETNOM KOLU IPMSM-A PRIMENOM FEA
}

\section{LOCAL IRON LOSS POWER DENSITY CALCULATION OF IPMSM USING FEA}

\author{
Milica Banović, Dejan Jerkan, Fakultet tehničkih nauka, Novi Sad
}

\begin{abstract}
Oblast - ELEKTROTEHNIKA I RAČUNARSTVO
Kratak sadržaj - U radu je napravljen pregled najzastupljenijih modela proračuna gubitaka u magnetnom kolu električnih mašina. Na primeru sinhronog motora sa utisnutim stalnim magnetima (IPMSM), uz primenu metode konačnih elemenata (FEA), izvršen je proračun lokalne raspodele gustine snage magnetnih gubitaka. Pored ukupnih gubitaka, izračunate su i njegove pojedinačne komponente (histerezisni gubici i gubici usled vrtložnih struja), kako za stator, tako $i$ za rotor. Korišćeni su standardni Jordan-ov model i modifikovani Jordan-ov model.
\end{abstract}

Ključne reči: FEA, IPMSM, gubici u gvožđu, histerezisni gubici, gubici usled vrtložnih struja.

Abstract - This paper gives an overview of most prominent iron loss calculation models used in electrical machine analysis. Local iron loss power density distribution of analysed IPMSM is calculated using FEA. Besides total iron losses, both hysteresis and eddy current losses contribution components are analysed and calculated separately for stator and rotor. Standard Jordan model and modified Jordan model were used.

Keywords: FEA, IPMSM, iron losses, hysteresis losses, eddy current losses

\section{UVOD}

Savremena istraživanja se intenzivno sprovode na polju razvijanja visoko efikasnih električnih pogona koji koriste sinhrone motore sa stalnim magnetima (IPMSM) i od kojih se zahteva velika gustina snage i optimizovane performanse u širokom opsegu brzina.

Zbog toga se velika pažnja posvećuje analizi i predikciji lokacije i intenziteta gubitaka u električnim motorima. Jedni od ključnih gubitaka u mašini jesu gubici u gvožđu tj. gubici u magnetnom kolu mašine.

Kod IPMSM gubici u gvožđu su najintenzivniji u zupcima i jarmu statora i površinskom delu jarma rotora, u okolini vrhova magneta, tamo gde je i promena magnetnog polja najizraženija. Pri radu na velikim brzinama, u oblasti slabljenja polja, posebno dolaze do izražaja gubici u gvožđu, koji tada mogu postati i najdominantnija komponenta gubitaka u mašini.

Inženjerski pristup nastoji da gubitke u gvožđu empirijski tretira razdvojeno (gubici usled makroskopskih vrtložnih struja i histerezisni gubici) u cilju pokušaja razdvajanja različitih fizičkih uticaja usled promene frekvencije i

\section{NAPOMENA:}

Ovaj rad proistekao je iz master rada čiji mentor je bio dr Dejan Jerkan, docent. varijacija magnetnog polja. Šta više, empirijski modeli gubitaka su pokazali veoma dobru korelaciju sa merenjima i pružaju veoma brz i jednostavan način procene gubitaka u gvožđu zbog čega se i dalje, najčešće koriste pri dizajnu električnih mašina.

\section{MODELI PRORAČUNA GUBITAKA U GVOŽĐU}

Analitički modeli gubitaka se uglavnom zasnivaju na empirijskoj Schteinmetz-ovoj jednačini ili na Jordanovom modelu. Osnovna prednost analitičkih modela je njihova jednostavnost i malo procesno vreme. Ovi modeli se pokazuju kao pouzdani u uslovima do vrednosti magnetne indukcije 1,5 T i frekvencije $700 \mathrm{~Hz}$.

\subsection{Modeli koji se zasnivaju na Schteinmetz-ovoj jednačini}

Originalni Schteinmetz-ov model [1] gubitke u gvožđu po jedinici zapremine $p\left[\mathrm{~mW} / \mathrm{cm}^{3}\right]$ izražava empirijskom jednačinom:

$$
p=C_{m} f^{\alpha} \hat{B}^{\beta}
$$

gde je $\widehat{B}$ amplituda i $f$ frekvencija prostoperiodičnog signala magnetne indukcije. U Schteinmetz-ovoj jednačini figurišu tri Schteinmetz-ova koeficijenta $C_{m}, \alpha$ i $\beta$, koji predstavljaju empirijski određene parametre materijala fitovanjem $B-H$ histerezisne krive. Eksponenti $\alpha$ i $\beta$ su racionalni brojevi u opsegu $\alpha \epsilon[1,3]$ i $\beta \epsilon[1,2]$.Najveća mana ovog modela jeste što je namenjen samo za situacije kada je magnetna indukcija prostoperiodičan signal, što često nije slučaj, naročito kod rotacionih mašina sa promenljivom geometrijom vazdušnog zazora izazvanom obrtanjem.

Modifikovani Schteinmetz-ov model [2] predstavlja jedan način proširenja originalnog modela za složenoperiodične talasne oblike. Osnovna ideja ovog modela je uvođenje ekvivalente frekvencije koja zavisi od izvoda $\frac{d B(t)}{d t}$ kao:

$$
f_{e q}=\frac{2}{\Delta B^{2} \pi^{2}} \int_{0}^{\mathrm{T}}\left(\frac{d B(t)}{d t}\right)^{2} d t
$$

gde je $\Delta B=B_{\max }-B_{\min }$ i $T$ period signala elektromagnetne indukcije. Modifikovana jednačina srednje snage gubitaka u gvožđu po jedinici zapremine $p_{v}\left[\mathrm{~mW} / \mathrm{cm}^{3}\right]$ se izražava jednačinom:

$$
p=C_{m} f_{e q}^{\alpha-1} \hat{B}^{\beta} \frac{1}{\mathrm{~T}}
$$

DC premagnetizacija se može uzeti u obzir korekcionim koeficijentom. Generalizovani Schteinmetz-ov model [5] iskazuje snagu gubitaka u gvožđu kao jednoznačnu funkciju magnetne indukcije:

$$
p=\frac{1}{T} \int_{0}^{T} C_{m}\left|\frac{d B(t)}{d t}\right|^{\alpha}|B(t)|^{\beta-\alpha} d t
$$


Ova jednačina ne uzima u obzir prethodne vrednosti elektromagnetne indukcije i ova jednačina je DC senzitivna tj. ne zahteva uvođenje korekcionog faktora usled postojanja DC komponente.

\subsection{Modeli koji se zasnivaju na Jordan-ovom modelu}

U [3] predstavljen je Jordan-ov model (pod kojim se veoma često u literaturi podrazumeva Schteinmetz-ov model) u kom su ukupni gubici u gvožđu razdvojeni na dva dela, na statičke histerezisne gubitke $p_{h}$ i dinamičke gubitke usled vrtložnih struja $p_{e d}$. Srednja vrednost snage gubitaka u gvožđu po jedinici mase $[\mathrm{W} / \mathrm{kg}]$ tokom jednog perioda osnovnog harmonika magnetne indukcije $T=\frac{1}{f}$ jednaka je:

$$
p=p_{h}+p_{e d}=c_{h} \hat{B}^{\alpha} f+c_{e d}^{\sin } \hat{B}^{2} f^{2}
$$

$\mathrm{U}$ ovom modelu histerezisni gubici se smatraju proporcionalni površini statičke $(f \rightarrow 0)$ histerezisne petlje. Histerezisni gubici rezultat su unutrašnjih procesa $u$ feromagnetskom materijalu koji rasipa energiju $e_{h}$ tokom jednog perioda $T$, uzimajući u obzir periodičnu promenu magnetne indukcije. $e_{h}$ zavisi od amplitude magnetne indukcije $\hat{B}$, ali i od prisustva viših harmonika u složenoperiodičnom signalu $B(t)$, koji će se oslikati u prisustvu manjih histerezisnih petlji unutar histerezisne petlje osnovnog harmonika. Za prostoperiodičnu promenu magnetne indukcije $B(t), e_{h}=c_{h} \hat{B}^{\alpha}$, gde je $c_{h}$ parametar materijala, a vrednost koeficijenta $\alpha \in[1.5,2]$.

Gubici usled vrtložnih struja $p_{e d}$ proporcionalni su kvadratu amplitude prostoperiodične magnetne indukcije $\hat{B}$ i

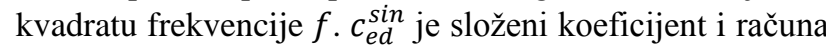
se kao $c_{e d}^{\sin }=\frac{\sigma \pi^{2} d^{2}}{6 \rho}$, gde je $\sigma$ - električna provodnost materijala lima, $\rho$-gustina materijala i $d$-debljina lima.

Gubici usled vrtložnih struja se mogu izračunati uz primenu Maksvelovih jednačina kao:

$$
p_{e d}=\frac{\sigma d^{2}}{12 \rho}\left(\frac{d B(t)}{d t}\right)^{2} .
$$

Ovaj model je jedan od najčešće korišćenih u praksi i veoma često, kada je nesinusoidalnost talasnog oblika magnetne indukcije izražena, gubici usled vrtložnih struja se računaju kao suma gubitaka usled vrtložnih struja za svaki red harmonika ponaosob. Tada, srednja vrednost snage gubitaka u gvožđu po jedinici mase $[\mathrm{W} / \mathrm{kg}]$ jednaka je:

$p=p_{h}+p_{e d}=c_{h} \widehat{B}^{\alpha} f+\sum_{i=1}^{n} c_{e d}^{\sin } \widehat{B}_{\imath}^{2} f_{i}^{2}$,

gde je $i$ red harmonika. Pry i Bean [4] su predložili jedan način za korekciju Jordan-ovog modela, uvođenjem empirijskog korekcionog faktora $\mu_{\text {exc }}$ (excess loss factor). Modifikovana je jednačina ukupnih gubitaka u gvožđu, za sinusoidalni talasni oblik magnetne indukcije, kao:

$$
\begin{gathered}
p=p_{h}+p_{e d}=c_{h} \hat{B}^{\alpha} f+\mu_{\text {exc }} c_{e d}^{\sin } \hat{B}^{2} f^{2}, \text { gde je } \\
\mu_{\text {exc }}=\frac{p_{\text {mereno }}}{p_{\text {proračunato }}}>1 .
\end{gathered}
$$

Drugi pristup za poboljšanje Jordan-ovog modela predlažio je Bertotti uvođenjem dodatnih gubitaka $p_{\text {exc }}$ kao funkciju frekvencije i amplitude elektromagnetne indukcije. Bertotti-ev model ukupne gubitke u gvožđu tretira kao zbir histereznih gubitaka $p_{h}$, gubitaka usled vrtložnih struja $p_{e d}$ i dodatnih gubitaka $p_{\text {exc }}$ :

$$
p=p_{h}+p_{e d}+p_{\text {exc }}=c_{h} \hat{B}^{\alpha} f+c_{\text {ed }}^{\text {sin }} \hat{B}^{2} f^{2}+c_{\text {exc }} f^{1.5} \hat{B}^{1.5} .
$$

Bertotti je uveo pojam magnetnih objekata i razvio teoriju kojom je fizički opisao i izveo funkcionalnost dodatnog koeficijenta $c_{\text {exc }}$ kao $c_{\text {exc }}=\sqrt{S V_{0} \sigma G}$, gde je $S$ површина poprečnog preseka lima, $G$ bezdimenzioni koeficijent $G \approx 0,136$ и $\sigma$ električna provodnost lima. $V_{0}$ karakteriše lokalnu statističku raspodelu koercitivnog polja uz uvažavanje veličine Vajsovih domena.

Originalni Bertotti-ev model podrazumeva sinusoidalnu magnetizaciju ili vrlo malo prisustvo izobličenja i bilo je potrebno proširiti Bertotti-ev model za slučaj nesinusoidalnog signala elektromagnetne indukcije.

Fiorillo i Novikov [6], a kasnije i Barbisio [7] su razvili originalnu Bertotti-evu formulu gubitaka u gvožđu tako da važi za svaki talasni oblik magnetne indukcije.

\section{PRAKTIČAN PRIMER}

Postupci za proračun gubitaka u gvožđu, koji su zasnovani na Jordan-ovim modelima, u ovom odeljku će biti primenjeni i verifikovani na primeru IPMSM. Reč je o motoru namenjenom širokom opsegu brzina, što proračun gubitaka čini još izazovnijim zadatkom.

Odabrani sinhroni motor namenjen je za pogon električnih uređaja za široku upotrebu, kao što je mašina za pranje (sušenje) veša. Napaja se iz statičkog energetskog pretvarača, a sam pogon je realizovan bez davača pozicije/brzine tj. reč je o sensorless pogonu relativno niskih performansi ali namenjenom za masovnu upotrebu u širokom opsegu brzina i momenta. Motor je osmopolni, trofazni, sa koncentrisanim statorskim namotajem načinjenim od aluminijuma. Sprega namotaja je zvezda, za nominalni napon od $200 \mathrm{~V}$. Spoljašnji prečnik statorskog lim paketa iznosi $102 \mathrm{~mm}$. Utisnuti stalni magneti su izrađeni od ferita. Nominalna brzina obrtanja motora je $5000 \mathrm{o} / \mathrm{min}$. Za brzine preko nominalne pogon je realizovan implementacijom slabljenja polja putem injektovanja negativne struje po $d$ osi.

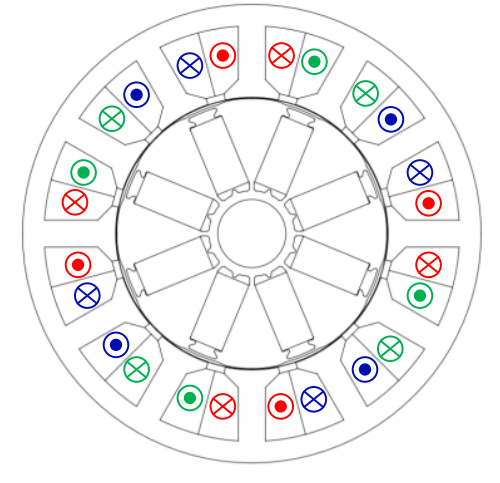

Slika 1. Izgled poprečnog preseka motora

Na slici 1 je prikazan poprečni presek lim paketa analizirane mašine sa principskom dispozicijom statorskog trofaznog namotaja, koji je izveden kao koncentrični. Nad modelom motora, kreiranim u programskom paketu FEMM 4.2. [8] izvršene su magnetostatičke simulacije kojima se oponaša rad motora u režimu idealnog praznog hoda, za različite brzine obrtanja, koje se kreću u opsegu 5000 $16000 \mathrm{o} / \mathrm{min}$. Kao odziv ovih simulacija se dobijaju vrednosti vektora magnetske indukcije u svakom od konačnih elemenata, koji se zatim koriste za proračune lokalnih vrednosti snage gubitaka po priloženim modelima. 
$\mathrm{Na}$ slici 2 je prikazan odziv magnetostatičke simulacije kojom se oponaša rad motora u režimu praznog hoda pri brzini obrtanja od $5000 \mathrm{o} / \mathrm{min}$. Ovaj radni režim predstavlja gornju granicu brzine pri kojoj se još uvek ne primenjuje slabljenje polja injektovanjem negativne struje po $d$ osi.

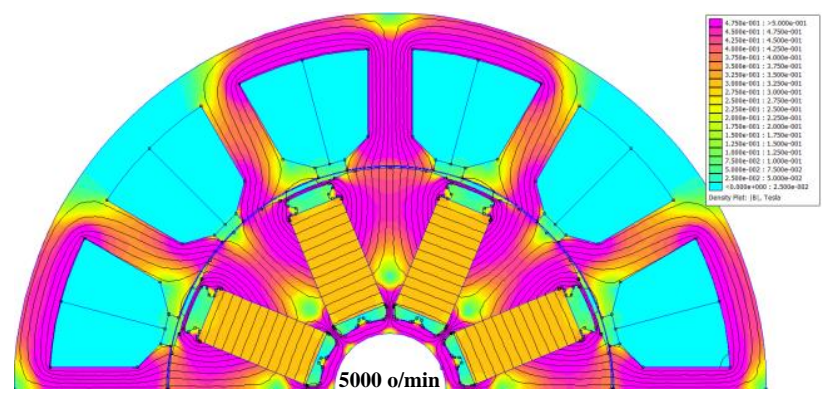

Slika 2. Simulacija za brzinu obrtanja $5000 \mathrm{o} / \mathrm{min}$

$\mathrm{Na}$ slici 3 su prikazani histerezisni gubici u magnetnom kolu statora u zavisnosti od brzine obrtanja. U oblastima brzina do $5000 \mathrm{o} / \mathrm{min}$ je primetan gotovo linearan porast, dok se u oblastima slabljenja polja za brzine preko $5000 \mathrm{o} / \mathrm{min}$ beleži njihov blagi pad. U oblasti brzina koje su manje od $5000 \mathrm{o} / \mathrm{min}$ nije primenjivano slabljenje polja, pa histerezisni gubici rastu sa porastom frekvencije od koje su linearno zavisni. Za brzine preko $5000 \mathrm{o} / \mathrm{min}$ je primenjeno slabljenje polja injektovanjem negativne struje po $d$ osi, usled kojeg dolazi do bržeg pada vrednosti indukcije u odnosu na porast frekvencije, pa otuda i pad histerezisnih gubitaka.

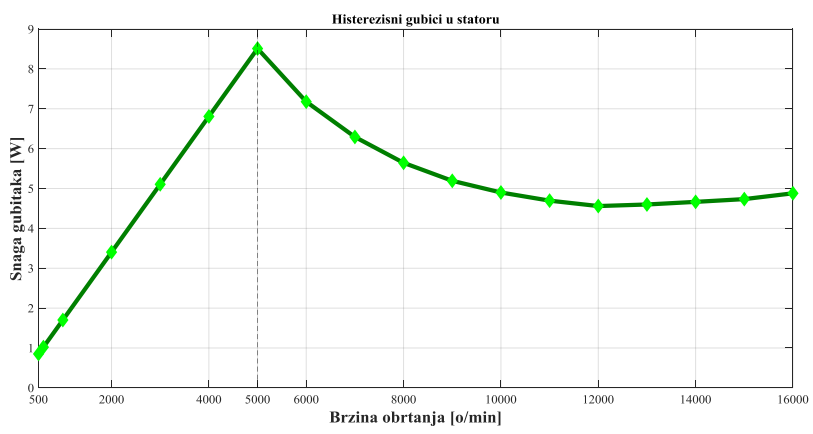

Slika 3 Histerezisni gubici u statoru po Jordan-ovom modelu proračuna

Na slici 4 su prikazani histerezisni gubici u magnetnom kolu rotora u zavisnosti od brzine obrtanja. Ponovo je u oblastima brzina do $5000 \mathrm{o} / \mathrm{min}$ očit praktično linearan porast ovih gubitaka, dok se u oblastima brzina preko $5000 \mathrm{o} / \mathrm{min}$, za razliku od histerezisnih gubitaka u magnetnom kolu statora, beleži njihov značajan porast. Pojašnjene ovog fenomena se pronalazi u činjenici da slabljenje polja, koje se izvodi u cilju smanjenja magnetnog polja $u$ statoru ne manifestuje $u$ značajnoj meri u magnetnom kolu rotora, te se sa porastom frekvencije povećavaju i histerezisni gubici.

Važno je primetiti i da je frekvencija promene magnetnog polja u površinskom sloju rotora, $u$ kojem su inače ove varijacije polja dominantno grupisane, tačno tri puta veća od frekvencije promene polja u statoru, što se objašnjava postojanjem tri statorska žleba po paru polova, koji svojom geometrijom unose varijacije u magnetnom polju rotora tačno tri puta u električnoj periodi.

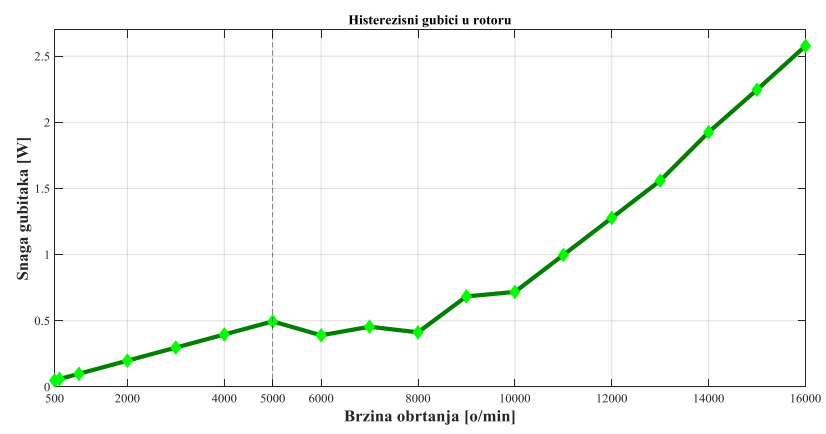

Slika 4 Histerezisni gubici u rotoru po Jordan-ovom modelu proračuna

Na slici 5 su prikazani gubici usled vrtložnih struja u magnetnom kolu statora u zavisnosti od brzine obrtanja, primenom Jordan-ovog i modifikovikovanog Jordan-ovog modela proračuna. Podsećanja radi, modifikovani model praktično unosi razlike samo u proračunu gubitaka usled vrtložnih struja. Primetan je porast gubitaka sa porastom brzine primenom oba modela, jer je zavisnost ovih gubitaka od frekvencije značajno izraženija od histerezisnih gubitaka. Očekivano je i da modifikovani Jordan-ov model daje veće vrednosti gubitaka, jer uvažava udeo harmonijskog izobličenja vektora magnetne indukcije.

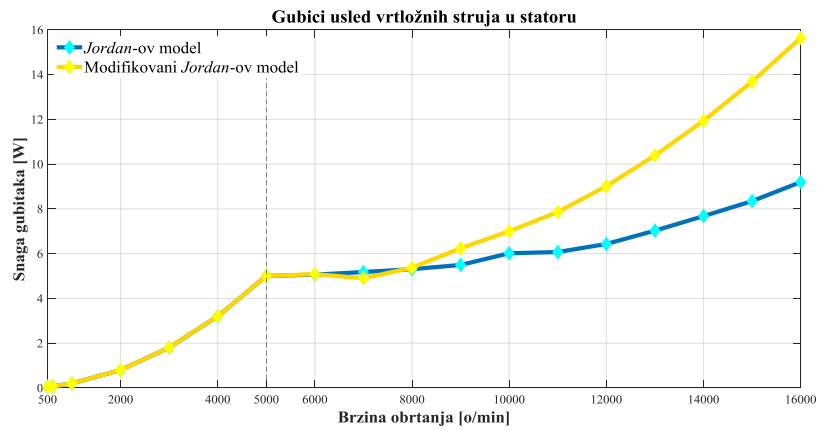

Slika 5 Gubici usled vrtložnih struja u statoru: Uporedni prikaz Jordan-ovog i modifikovanog Jordan-ovog modela

Na slici 6 su prikazani gubici usled vrtložnih struja u magnetnom kolu rotora u zavisnosti od brzine obrtanja, primenom Jordan-ovog i modifikovanog Jordan-ovog modela proračuna. Primetan je značajan porast ovih gubitaka sa porastom brzine, što je i očekivano, u istom smislu kao što je to bio slučaj sa ovim gubicima $u$ magnetnom kolu statora, uz napomenu o tri puta većoj frekvenciji varijacije magnetnog polja u površinskom sloju rotora $\mathrm{u}$ odnosu na frekvenciju u statoru.

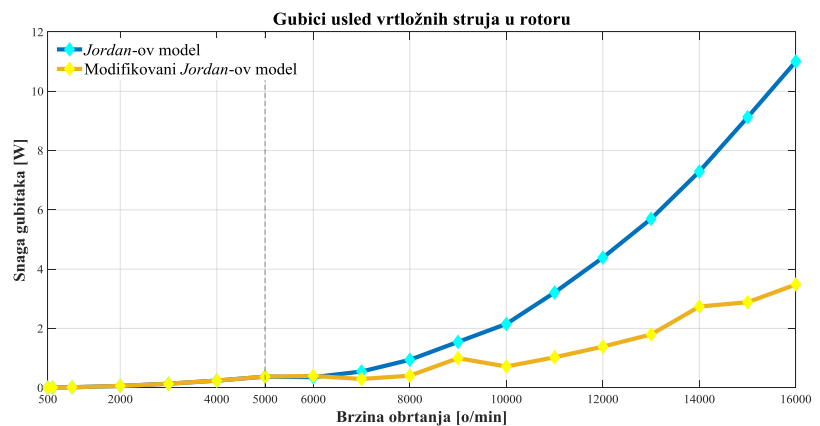

Slika 6 Gubici usled vrtložnih struja u rotoru: Uporedni prikaz Jordan-ovog i modifikovanog Jordan-ovog modela 
Na slici 7 su uporedno prikazani gubici u gvožđu za različite brzine obrtanja motora, primenom Jordan-ovog i modifikovanog Jordan-ovog modela proračuna. Primetno je da dva modela proračuna vrlo malo odstupaju sa aspekta ukupnih gubitaka u magnetnom kolu motora, ali da lokalno daju drugačije rezultate, što je očigledno sa prethodno prikazanih slika. Za motore koji rade u širokom opsegu brzina je važna i lokalna raspodela gubitaka, zbog pravilnog dimenzionisanja sistema hlađenja, tako da se ispostavlja da je od značaja lokalna distribucija gubitaka, koja je vernije prikazana primenom modifikovanog Jordan-ovog modela.

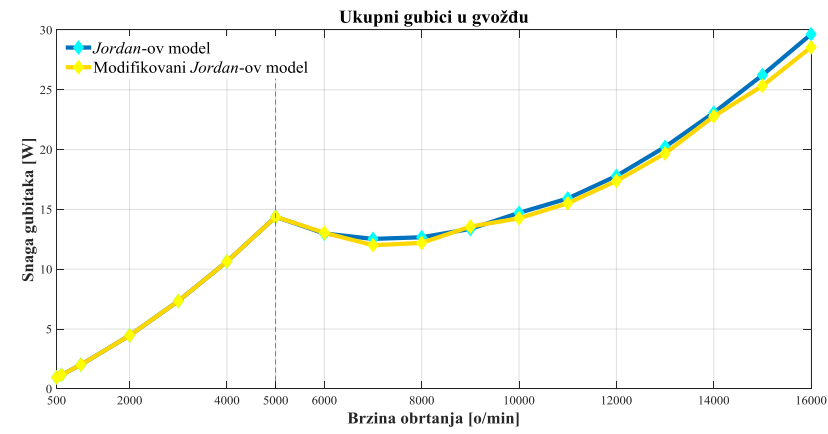

Slika 7. Ukupni gubici u gvožđu: Uporedni prikaz Jordan-ovog i modifikovanog Jordan-ovog modela

\section{ZAKLJUČAK}

$\mathrm{U}$ radu su prikazani postupci proračuna gubitaka u magnetnom kolu električnih mašina, koji se zasnivaju na Jordanovim modelima. Ovi modeli su primenjeni u izračunavanju lokalne raspodele snage gubitaka u sinhronoj mašini sa utisnutim stalnim magnetima na rotoru. Pošto je reč o mašini koja tokom rada pokriva širok opseg brzina, veoma je važno poznavati raspodelu gubitaka, koja značajno varira sa promenom brzine obrtanja motora. Priloženi modeli proračuna gubitaka su iskorišćeni u lokalnom obliku, primenom rezultata dobijenih metodom konačnih elemenata. Metoda konačnih elemenata daje izuzetno detaljnu magnetnu sliku motora, nudeći mogućnost rekonstruisanja talasnih oblika vektora magnetne indukcije u svakom od pojedinačnih konačnih elemenata. $\mathrm{Na}$ osnovu poznavanja lokalnih vrednosti vektora magnetne indukcije, ali i njegovih talasnih oblika se dobijaju i lokalne raspodele snage gubitaka.

Uporedno su prikazani gubici (histerezisni i usled vrtložnih struja) u magnetnom kolu statora i rotora, kao i ukupni gubici u magnetnom kolu celog preseka motora. Pokazuje se da ima vrlo malih odstupanja u ukupnim gubicima, ali da se pojedinačne komponente razlikuju u zavisnosti od primenjenog modela proračuna. Ovim se potvrđuje da je izuzetno važno poznavati lokalnu distribuciju gubitaka, jer od njih direktno zavisi i lokalna temperatura magnetnog kola. Ukoliko dolazi do lokalnog pregrevanja, o tome se mora voditi računa prilikom projektovanja rashladnog sistema. Primetan je značajan porast gubitaka u rotoru sa porastom brzine obrtanja, a budući da su ovi gubici skoncentrisani $\mathrm{u}$ vrlo tankom površinskom sloju magnetnog kola rotora, može se zaključiti da je ovaj deo motora potencijalno najviše termički ugrožen.

\section{LITERATURA}

[1] C. Steinmetz, „On the law of hysteresis,” American Institute of Electrical Engineers., vol. 9, pp. 3-64, 1892.

Reprinted: Proceedings of the IEEE, vol. 72, no. 2, 1984

[2] Reinert, J., Brockmeyer, A., \& De Doncker, R. W. A. A. (2001). Calculation of losses in ferro- and ferrimagnetic materials based on the modified Steinmetz equation.

[3] H. Jordan, Die ferromagnetischen Konstanten für schwache Wechselfelder, Elektr. Nach. Techn., vol. 1, p. 8,1924

[4] R. H. Pry and C. P. Bean, Calculation of the energy loss in magnetic sheet materials using a domain model, Journal of Applied Physics, vol. 29, no. 3, pp. 532533, Mar. 1958.

[5] J. Li, T. Abdallah, and C. Sullivan, Improved calculation of core loss with nonsinusoidal waveforms, in Industry Applications Conference, 2001. Thirty-Sixth IAS Annual Meeting. Conference Records, vol. 4, 2001, pp. 22032210

[6] F. Fiorillo and A. Novikov, "An improved approach to power losses in magnetic laminations under nonsinusoidal induction waveform," IEEE Trans. Magn., vol. 26, no. 5, 1990.

[7] E. Barbisio, F. Fiorillo, and C. Ragusa, "Predicting loss in magnetic steels under arbitrary induction waveform and with minor hysteresis loops," IEEE Trans. Magn., vol. 40, no. 4, 2004.

[8] www.femm.info/wiki/HomePage

\section{Kratka biografija:}

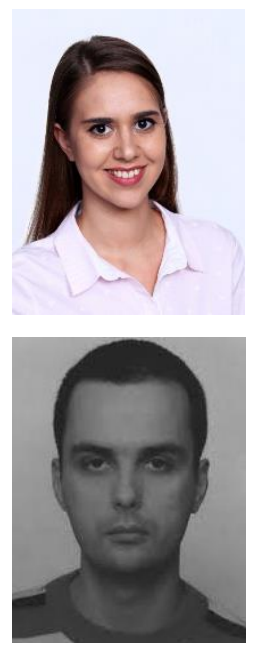

Milica Banović rođena je u Novom Sadu 1996. godine. Diplomirala je na Fakultetu tehničkih nauka u Novom Sadu 2019. godine. Master rad iz oblasti Elektrotehnike i računarstva - Energetska elektronika i električne mašine odbranila je 2020. godine.

kontakt: banovicmilicaa@gmail.com

Dejan Jerkan je docent na Fakultetu tehničkih nauka u Novom Sadu, na Katedri za Energetsku elektroniku i pretvarače. Oblast interesovanja su mu modelovanje i dijagnostika električnih mašina, kao i metoda konačnih elemenata. 